\title{
Replies to Wang, Speaks, and Pautz
}

Philosophy and Phenomenological Research (forthcoming)

Trenton Merricks

University of Virginia

\section{Reply to Wang}

A logically valid argument preserves truth in virtue of form. A modally valid argument is such that, necessarily, if its premises are true then its conclusion is true. I say that logically valid arguments express modally valid arguments. That is, I say that the sentences that are the premises and conclusion of a logically valid argument express propositions, and those propositions are themselves the premises and conclusion of a modally valid argument.

Wang objects: "Merricks's view, unlike those of his opponents, cannot explain something that cries out for explanation: why any logical validity guarantees the existence of a corresponding modal validity" and "[Merricks] cannot explain why truthpreservation in virtue of form tracks necessitation relations between propositions." She even says that given my view of the nature of propositions, it is a "huge coincidence" that logically valid arguments express modally valid arguments. 
My reply to Wang's objection starts with X-Logic (cf. 64-5). ${ }^{1}$ By the lights of Xlogic, 'coyotes howl' is a logical consequence of 'dogs bark'. Relatedly, 'coyotes howl' is true in every model for X-logic in which 'dogs bark' is true. But X-logic is mistaken and its models defective. This is because, despite what X-logic says, 'coyotes howl' is not really a logical consequence of 'dogs bark'.

I think that one good reason for denying that 'coyotes howl' is a logical consequence of 'dogs bark' is that the truth of 'dogs bark' does not guarantee the truth of 'coyotes howl'. So I conclude that an argument is logically valid only if the truth of its premises guarantees the truth of its conclusion (cf. 39-40; 61-71). In the book, I argue that the relevant guarantee is modal (64-71). But there is more than one way to understand this modal guarantee.

The most widely endorsed way says that logically valid arguments are themselves (in virtue of their form) modally valid (61-2). But every logically valid argument has sentences as its premises and conclusion (34-60); no modally valid argument has sentences as its premises and conclusion (4-10); so no logically valid argument is modally valid (62-7). So we must reject the most widely endorsed way.

There are modally valid arguments. Propositions are the premises and conclusions of modally valid arguments (1-29). The premises and conclusion of a logically valid argument express propositions (39-40). Building on these points, and those above, I argue that what it is for the truth of a logically valid argument's premises to guarantee the truth of its conclusion is for that logically valid argument to express (in virtue of its form) a modally valid argument (39-40, 63-64).

\footnotetext{
${ }^{1}$ Unless otherwise noted, all page references are to Propositions.
} 
To summarize: An argument counts as logically valid only if the truth of its premises guarantees the truth of its conclusion. What it is for the truth of a logically valid argument's premises to guarantee the truth of its conclusion is for that argument to express a modally valid argument. So if an argument does not express a modally valid argument, then that argument does not count as being logically valid. This is why it is not a "huge coincidence" that logically valid arguments express modally valid arguments.

\section{II}

Here is Zippism: Zipping relates objects to properties. Neither Zipping's existence nor its relating an object to a property depends on anything that agents do. Every state of affairs of an object's being related by Zipping to a property essentially represents that object as having that property. That is just how Zipping works; nothing explains how Zipping manages to work this way. Propositions are states of affairs involving Zipping. For example, the proposition that $O$ is $F$ is the state of affairs of $O$ 's being related by Zipping to the property $\mathrm{F}$.

The main motivation for structured propositions is their promise to deliver a full explanation of how a proposition manages to represent things as being a certain way, that is, an explanation that does not invoke unexplained powers relevant to representation enjoyed by a proposition's constituents or structure (or the proposition itself) (133-156; 201n6). Zipping has unexplained powers relevant to representation. Thus Zippismthough itself a version of structured propositions - runs counter to the main motivation for structured propositions. So I set Zippism aside (154). 
Wang thinks I was too hasty. She is absolutely right. After all, I deny that there is any explanation at all - much less a full explanation - of how a proposition manages to represent things as being a certain way. So Zippism's failure to deliver a full explanation cannot be the reason that I myself reject Zippism, despite the fact that-see Section V of my reply to Speaks - it is a good reason for almost all defenders of structured propositions to reject Zippism.

Here is why I reject Zippism. Zippism says that the proposition that $O$ is $F$ has $\mathrm{O}$ itself as a constituent. Thus Zippism is vulnerable to the second main line of argument in the book against structured propositions, the line of argument that focuses on the view that a singular structured proposition has the entity that it is directly about as a constituent. All of Chapter 5 is dedicated to this line of argument. Thus all of Chapter 5 gives reasons that I reject Zippism.

Zippism, as described above, is a species of neo-Russellian structured propositions. We should also consider species of neo-Fregean structured propositions that rely on Zipping. Such a species might say, for example, that the proposition that $O$ is $F$ is identical with the state of affairs of the Fregean sense of ' $\mathrm{O}$ ' being related by Zipping to $\mathrm{F}^{2}$ Neo-Fregean versions of Zippism are immune to the arguments of Chapter 5. But-so I argue - neo-Fregeanism is false $(57-69 ; 128)$. So I conclude that neo-Fregean Zippism is false. ${ }^{3}$

\footnotetext{
2 The Fregean sense of ' $O$ ' must have powers relevant to representation, so that, for example, it somehow "hooks onto" O, as opposed to some other object. Those powers are distinct from the powers enjoyed by Zipping. If a Fregean sense's powers are unexplained, then neo-Fregean Zipping requires at least two different kinds of unexplained powers relevant to representation.

${ }^{3}$ See $\S$ I of my reply to Pautz, below, for another reason to reject all versions of Zippism.
} 
Wang says that the prospects for explaining why language is compositional "certainly [are] more promising on Zippism than on Merricks's primitivism." She then offers the beginnings of such an explanation with:

For example, we might say that a simple sentence consisting of a proper name followed by a verb... expresses the proposition formed by zipping the referent of the name to the property expressed by the verb. In contrast, on Merricks's primitivism, there is no such story.

I reply that I can offer a story that - with regard to explaining why language is compositional-is just as good: a simple sentence consisting of a proper name followed by a verb expresses the proposition that (primitively) represents the referent of that name as exemplifying the property expressed by that verb.

\section{Reply to Speaks}

\section{I}

An argument is modally valid just in case, necessarily, if its premises are true, then its conclusion is true. A conclusion cannot be true unless it exists. So, necessarily, if the premises of a modally valid argument are true, then that argument's conclusion exists.

With this in mind, I say:

As we saw above, the truth of the premises of a modally valid argument necessitates the existence of that argument's conclusion. I think that this should have an explanation. Suppose that all the premises and conclusions of modally valid arguments exist necessarily. Then the conclusion of each modally valid argument exists necessarily. Then, necessarily, if a modally valid argument's premises are true, its conclusion exists. In this way, the necessary existence of all the premises and conclusions of modally valid arguments directly and elegantly explains why the truth of a modally valid argument's premises necessitates the existence of its conclusion. (19) 
Speaks seems to agree that the following thesis should have an explanation: necessarily, if the premises of a modally valid argument are true, then that argument's conclusion exists. Speaks also agrees that if all propositions existed necessarily, this would explain that thesis. Even so, Speaks objects to the reasoning in the above passage.

His objection is that the explanation offered in the above passage is redundant, and so not motivated by the need for an explanation. For Speaks says that there isbefore we ever get to the explanation offered in the above passage - an "obvious explanation" of that thesis. That explanation, he says, just is the argument for that thesis with which this section opened:

As just noted, [the claim that, necessarily, if a proposition is true, then it exists] plus the definition of modal validity, trivially entails the truth of [that thesis]. So there is no big mystery about why [that thesis] is true; its truth seems to be sufficiently explained by our property actualist principle and the definition of modal validity.

Speaks's objection seems to presuppose that an argument for a thesis is ipso facto an explanation of that thesis. I deny that presupposition. Imagine an argument that defends both conjuncts of this conclusion: abstract objects exist and there is no explanation of their existence. (Perhaps this argument is being used to oppose the Principle of Sufficient Reason.) This is an argument for (among other things) the existence of abstract objects. But this argument - an argument for (among other things) there being no explanation of the existence of abstract objects - is not an explanation of the existence of abstract objects. ${ }^{4}$

\footnotetext{
${ }^{4}$ See my reply to Pautz, §II, for another counterexample to Speaks's seeming presupposition.
} 
Let Existentialism be the conjunction of two claims. First, propositions have constituents; in particular, they have the entities that they are directly about as constituents. Second, if propositions have constituents, then propositions cannot exist without their constituents. Speaks says that I argue against Existentialism. But the only sense in which I argue against Existentialism is that I argue against its first conjunct. ${ }^{5}$ So I think it is more precise to say that I argue against the claim that propositions (have constituents and) have the entities that they are directly about as constituents. That is, I argue against neo-Russellian singular propositions (cf. 157-162).

I give a number of arguments against neo-Russellian singular propositions in Chapter 5. Here is an outline of the main argument that Speaks addresses in his discussion of Existentialism. Every logically valid argument expresses a modally valid argument. This implies — so I argue — that logically valid sentences (e.g., sentences with the logical form $P$ or $\sim P$ ) express necessarily true propositions. There are logically valid sentences that express propositions directly about contingently existing entities. So there are necessarily true propositions directly about contingently existing entities. Necessarily, if a proposition is true, then that proposition exists. So there are necessarily existing propositions directly about contingently existing entities. This implies that neoRussellianism about singular propositions is false. (For the full argument, see 164-5.)

As Speaks notes, this argument succeeds only if, necessarily, if a proposition is true, then that proposition exists. Speaks points out that there are philosophers - his

\footnotetext{
${ }^{5}$ I think its second conjunct is true (because it has a false antecedent). Speaks puts that conjunct this way: "Propositions cannot exist without their constituents." I prefer my way of putting it since my way makes it clear that neither conjunct is redundant.
} 
“Type 1 Russellians"- who deny this claim. I too point this out (180-182). I even add that those philosophers will reject a premise that I rely on to get to this claim. That premise is that, necessarily, if an entity exemplifies a property, then that entity exists. ${ }^{6}$

I also say why I find Type 1 Russellians to be puzzling (181-2). They defend the conclusion that some propositions exist contingently with reasoning such as: necessarily, that Socrates does not exist has Socrates as a constituent; necessarily, if an entity is a constituent of a proposition, then that entity exists; Socrates exists contingently; therefore, that proposition exists contingently. So Type 1 Russellians say that, necessarily, if an entity is a constituent of a proposition, then that entity exists. But Type 1 Russellians deny that, necessarily, if an entity is true, then that entity exists. But if a non-existing entity can be true, why can't a non-existing entity be a constituent of a proposition $?^{7}$

Set my puzzlement aside. The point remains that Type 1 Russellians will not be persuaded by any argument that relies on the thesis that, necessarily, if a proposition is true, then that proposition exists. So Type 1 Russellians will not be persuaded by the above argument against neo-Russellian singular propositions. I shall return to this point below. But first I want to focus on a second thesis relied on by the above argument. This is the thesis that some arguments are modally valid. For my defense of the claim that logically valid arguments express modally valid arguments - a claim crucial to the above argument-starts with this second thesis (1-64; reply to Wang, §I).

Indeed, this is where the whole book starts. The Introduction begins:

\footnotetext{
${ }^{6}$ I think a proposition is true if and only if: first, it exemplifies a property to the effect that it represents things as being a certain way and, second, things are that way $(20-21 ; 181)$.

${ }^{7}$ My own view is that only existing entities can be true and only existing entities can be constituents of propositions (181-2).
} 
Let an argument be modally valid just in case, necessarily, if its premises are true, then its conclusion is true. This book begins with the assumption that some arguments are modally valid. (xiii)

And Chapter 1 begins:

An argument is modally valid just in case, necessarily, if its premises are true, then its conclusion is true. This book's starting point is that there are some modally valid arguments. (1)

Speaks's "Type 2 Russellians" deny that some arguments are modally valid. But

they add: arguments have premises and conclusions; those premises and conclusions have actual truth conditions; for some arguments, necessarily, if the actual truth conditions of their premises are satisfied, then the actual truth conditions of their conclusion are satisfied. Speaks points out — as do I (17) — that this delivers a "modal connection" between how things must be in order for certain actual truth conditions to be satisfied. ${ }^{8}$ He then objects: "What Merricks must do-and I think does not do-is explain why this modal connection is not enough."

"Not enough" for what?

This modal connection is not enough to deliver entailment relations that hold between propositions but not sentences. After all, sentences, no less than propositions, have actual truth conditions. ${ }^{9}$ So sentences and propositions alike stand in - to use

\footnotetext{
${ }^{8}$ I say that there are some modally valid arguments. Speaks's "Type 2 Russellians" deny that there are modally valid arguments (although they add (and I agree) that there are modal connections between ways things are). This is a straightforward disagreement. In the text I describe this disagreement in my way - as opposed to in Speaks's way - because I think that Speaks's terminology can obscure how straightforward this disagreement is. (Here is this disagreement put in Speaks's terminology: I say that there are arguments whose premises entail ${ }_{2}$ their conclusions, and Type 2 Russellians deny this (although they add (and I agree) that there are arguments whose premises entail 1 their conclusions).)

${ }^{9}$ Perhaps sentences have truth conditions only in contexts of use. If so, then they stand in relations of Speaks's entailment ${ }_{1}$ only in contexts of use. By the same token, they stand in relations of logical consequence only in contexts of use (39-40).
} 
Speaks's terminology - relations of "entailment ${ }_{1}$." I think that this should bother Speaks, who says:

The claim that relations of logical consequence between sentences are distinct from relations of entailment between propositions will, I hope, not come as a shock to too many defenders of the Russellian orthodoxy. That distinction was one of the first lessons drilled into me in graduate school.

But set this point aside. For this point does not directly address the objection behind Speaks's remark about "not enough."

Here, I think, is that objection. I must-but do not-convince Type 2 Russellians that the sort of modal connection noted above is "not enough" to accommodate their “intuitions about 'following of necessity'." This is because I must - but do not - force Type 2 Russellians, by dint of their own "intuitions about 'following of necessity'," to endorse the claim that there are modally valid arguments.

I deny that I must do these things. And I freely confess that I cannot force Type 2 Russellians to agree - by dint of their own intuitions or otherwise - that there are modally valid arguments. Nor can I force Type 1 Russellians to accept the claim that, necessarily, if an entity exemplifies a property, then that entity exists. So-as Speaks emphasizes certain Russellians have already "staked out" one position or another that will allow them to resist the argument outlined at the start of this section against neo-Russellian singular propositions.

Speaks takes this to be an indictment of that argument. But I do not. For this would be an indictment only if the only good reasons to present an argument against a view were to convince that view's most careful defenders that they are mistaken, or instead to force them to say something that they have never said before. But, happily, 
those are not the only good reasons to present an argument against a view. There are many good reasons.

For example, I think that an argument against a view is worth presenting if its premises are reasonable and, moreover, one could find those premises reasonable without having an opinion, one way or the other, on the view in question. Such an argument might not persuade a veteran defender of that view. But such an argument might persuade someone who has no prior opinion of that view, might inform someone who wants to know what counts against that view, and so on. Such an argument might be especially worth presenting alongside other arguments against that view, particularly if all those arguments are mutually reinforcing in some way or other. Such an argument might even be the way in which someone discovers that that view is false!

I think this is a reasonable premise: some arguments are such that, necessarily, if their premises are true, then their conclusion is true; that is, some arguments are modally valid. Of course, not everyone endorses this premise, as witness Type 2 Russellians. But, as I show (1-4, 61-4), many philosophers have asserted, in one way or another, that some arguments are modally valid. I think that this is part of what makes it reasonable to start with the claim that some arguments are modally valid. But, obviously, I do not argue for that claim on the basis of what many philosophers assert, as if that claim were one of my conclusions. On the contrary, and to repeat, that there are modally valid arguments is my starting point.

Again, the following is a reasonable premise: some arguments are modally valid. So too is this premise: something must exist in order to exemplify a property. These premises lead to the conclusion that the neo-Russellian account of singular propositions is 
false. Some philosophers have endorsed these premises for reasons having nothing to do with their views on the metaphysics of propositions, much less on neo-Russellian singular propositions in particular. ${ }^{10}$ So I think that an argument against neo-Russellian singular propositions that uses these premises is worth presenting-especially alongside other arguments attacking neo-Russellianism from multiple directions.

Here is an outline of another argument against neo-Russellian singular propositions. Let 'Noman' name the person who would have developed from sperm S and egg E, had S fertilized E. Noman does not exist. 'Noman does not exist' expresses a true proposition that is directly about the non-existing Noman. This rules out neoRussellian singular propositions. (For the full argument, see 173-8.)

With this argument in mind, Speaks says that I need to provide a "semantics of 'Noman"” that is "unavailable to the Russellian." I deny that I need to provide such a semantics in order to prosecute this argument. But, in light of this argument's conclusion, I am pleased to offer the following claim about the semantics of 'Noman', which claim is unavailable to the Russellian: 'Noman' can be used to express propositions that are directly about the non-existing Noman.

We can express propositions that are directly about the non-existing Noman. So there are propositions that are directly about the non-existing Noman. This is consistent with the claim that an entity must exist in order to stand in a relation. This is because a proposition's being directly about an entity does not imply that that proposition stands in a relation to that entity. Rather, so I argue, to say that a proposition is directly about an

\footnotetext{
${ }^{10}$ For example, Bergmann (1996) defends the claim that something must exist in order to exemplify a property without ever alluding to the metaphysics of propositions. And Propositions presents a wide range of philosophers who say there are modally valid arguments for reasons other than a rejection of neoRussellian singular propositions (1-4; 61-62).
} 
entity is merely to partially describe how that proposition represents things as being (185189).

\section{III}

Jane uses 'the first proposition expressed by John on Tuesday' to fix the reference of ' $p$ '. John uses 'the first proposition denied by Jane on Monday' to fix the reference of ' $q$ '. First thing Monday, Jane denies the proposition that John's evidence justifies $p$. First thing Tuesday, John expresses the proposition that $q$ is about cats. All this implies that $p$ is a singular proposition about $q$, and $q$ is a singular proposition about $p$.

So there is some proposition $p$ and some numerically distinct proposition $q$ such that $p$ is a singular proposition about $q$ and $q$ is a singular proposition about $p$. The neoRussellian view of singular propositions implies that $q$ is a constituent of $p$ and $p$ is a constituent of $q$. If the constituents of a proposition are its parts, then that view violates Antisymmetry: $(x)(y)$ If $x$ is a part of $y$ and $y$ is a part of $x$, then $x=y$. I endorse Antisymmetry. So I conclude that if constituency is parthood, then neo-Russellianism is false.

Speaks objects:

... everyone who has tried in any serious way to develop the view that propositional constituency is parthood acknowledges that this view is apparently inconsistent with otherwise plausible mereological principles like Antisymmetry. The real debate is about whether the explanatory advantages of a mereological account of propositional constituency outweigh its revisionary costs. It would have been interesting to see engagement with this discussion rather than presentation of the apparent conflict as though this were the last word. 
It is false that I present the very real conflict here with Anti-Symmetry as "the last word."

Here is the passage in Propositions that immediately follows my pointing out that conflict:

The argument just given turns on the Antisymmetry of Parthood. This principle is widely endorsed. But not universally. Some hold that a statue $\mathrm{S}$ is not identical with the lump of clay L that 'constitutes' that statue. Moreover, some even add that - though $\mathrm{S}$ is not identical with $\mathrm{L}-\mathrm{L}$ is a part of $\mathrm{S}$ and $\mathrm{S}$ is a part of $\mathrm{L}$ (see, e.g., Thomson, 1998). Those who add this will reject the Antisymmetry of Parthood.

Those who reject the Antisymmetry of Parthood do so because they believe that there are cases of two numerically distinct objects that wholly overlap and are parts of each other. Even those who reject the Antisymmetry of Parthood would find the following case absurd: Lump of clay $\mathrm{L}^{*}$ constitutes the bottom half of $\mathrm{S}$, and so does not wholly overlap $\mathrm{S}$; $\mathrm{L}^{*}$ is not identical with $\mathrm{S} ; \mathrm{L}^{*}$ is a part of $\mathrm{S}$; and $S$ is a part of $L^{*}$.

With this in mind, recall the example in which $q$ is the proposition that John's evidence justifies $p$ and $p$ is the proposition that $q$ is about cats. Given the received view [i.e., the neo-Russellian account of singular propositions], $q$ is a part of $p$ and $p$ is a part of $q$. But, even given the received view, $p$ has parts that $q$ does not have and $q$ has parts that $p$ does not have. For example, given the received view, $q$ has John himself as a part but $p$ does not. So the received view implies that $p$ and $q$ are not identical and are parts of each other even though $p$ and $q$ do not wholly overlap. I say that the received view is no better than the absurd case of S and $\mathrm{L}^{*}$. (167)

After responding to an objection involving the transitivity of parthood, I conclude

this line of argument with:

I believe the Antisymmetry of Parthood. So I stand by the original version of the above argument against the received view that traded directly on that principle. But even those who reject the Antisymmetry of Parthood ought to endorse a version of that above argument. For even they ought to agree that if two objects do not wholly overlap, then those objects are not parts of each other. And the received view implies that that John's evidence justifies $p$ and that $q$ is about cats do not wholly overlap and are parts of each other. So all of us - friends and foes of the Antisymmetry of Parthood alike - ought to reject the received view. (1689) 
Here is what I mean by 'structured proposition'. A structured proposition is a proposition that results from uniting, somehow or other, entities like following: people and dogs and properties and relations, or perhaps Fregean senses of some or all of the former. By a proposition's 'constituents', I mean the entities thus united. ${ }^{11}$ (For more, see 123-129.) With what I mean by 'structured proposition' and 'constituent' in mind, I say: "The literature on structured propositions takes constituency to be either parthood or set membership" (169). And I add: "I cannot see what else a structured proposition's constituents could be, if not its parts or its members." 12

Suppose that a structured proposition's constituents are either its parts or its members. Then some version of the above argument can be run against every species of neo-Russellianism. Against those species that take constituents to be parts, we can run the argument exactly as above. Against those species that take constituents to be members, we can run the above argument once we substitute the Axiom of Regularity for the Antisymmetry of Parthood. This is because the Axiom of Regularity implies, among other things, that no set is a member of a member of itself (169; cf. 109, 113).

Speaks objects:

...Merricks's conception of the space of propositions seems a bit impoverished. It is simply not the case that the only alternatives in the literature on structured propositions identify propositional constituency with either parthood or set membership. Indeed, neither of the two most prominent recent attempts to give a theory of structured propositions - King's view of propositions as facts, and the view of Hanks and Soames that propositions are types of cognitive acts - fits either model. It is not easy to see how to run Merricks's argument here against either view.

\footnotetext{
11 Again, this is what I mean by 'constituents'. There are other reasonable meanings, some of which I explicitly note on 149-150 and at 169n8.

12 "More carefully, I cannot see what else a structured proposition's constituents could be if not its members, the members of its members (of its members), its parts, the parts of its parts (of its parts)...or some combination of these." (169n)
} 
King's view is that propositions are (Russellian) facts, that is, states of affairs. In Propositions, I say: "states of affairs have parts. For example, your sitting has both you and sitting as parts" (124). King agrees:

Let's call an object possessing a property or $\mathrm{n}$ objects standing in an n-place relation, or $\mathrm{n}$ properties standing in an n-place relation or etc. a fact. We'll call the objects, properties and relations that are parts of a fact its components. (King, 2007, 26)

So I think that if propositions are states of affairs, as King takes them to be, then the constituents of a proposition are parts of that proposition. ${ }^{13}$

Moreover, a version of the above argument against neo-Russellian singular propositions can be run against propositions-as-states-of-affairs without relying on the claim that the constituents of a state of affairs are its parts (or its members). To see this, suppose that World War II was a state of affairs (that is, a Russellian fact). And suppose that the Battle of the Bulge was a state of affairs that was a constituent of World War II. Obviously, there is no sense in which that battle and that war wholly overlap. So we should conclude that World War II was not a constituent of the Battle of the Bulge. This illustrates that if one state of affairs $\mathrm{x}$ is a constituent of - but does not in any sense wholly overlap-another state of affairs $y$, then it is false that $y$ is a constituent of $x$. And that is all we need to run a version of the above argument.

Speaks notes that Hanks (2015) and Soames (2015) take propositions to be cognitive act types. A cognitive act type is not an object that results from somehow

\footnotetext{
${ }^{13}$ Lewis $(1992,213)$ famously says that states of affairs involve "some sort of unmereological composition" and "that is a contradiction in terms." If Lewis's claim is correct, then there are no states of affairs, lest there be parts that are not parts. Lewis's claim presupposes uniqueness of composition and unrestricted composition, both of which are controversial.
} 
uniting entities like people and dogs and properties and relations or Fregean senses of some or all of the former. So - given what I mean by 'structured proposition' - the view that propositions are cognitive act types is not a view according to which there are structured propositions (cf. my remark about Soames's view at 137n). So my claim that the constituents of (what I call) a structured proposition are either its parts or its members is consistent with the claim that propositions are cognitive act types and have neither parts nor members.

\section{IV}

If propositions have logical form, then they can stand in relations of logical consequence. I argue that propositions cannot stand in relations of logical consequence (34-60). So I conclude that propositions do not have logical form. That is, I conclude that no proposition is literally the conjunction of two propositions, no proposition is literally the disjunction of two propositions, no proposition is literally the negation of another proposition, and so on.

The above reasoning began with:

The Conditional: If propositions have logical form, then they can stand in relations of logical consequence.

I say that the Conditional is obvious, and add: "for example, a proposition that had the logical form of the conjunction of two propositions would be the logical consequence of those two propositions" (78). Speaks is not convinced. He has doubts about the Conditional.

His doubts about the Conditional seem to be motivated by his assertions about 
"what proponents of the Russellian orthodoxy mean when they say that some propositions are literally negations, literally conjunctions, etc." And he suggests that my dispute with these proponents of the Russellian orthodoxy over the Conditional might be a "merely verbal dispute" about what "should be called "logical'."

So suppose that some "proponents of the Russellian orthodoxy" really do deny the Conditional. Suppose, that is, that they really do endorse the following two claims: first, some propositions are literally the conjunctions of other propositions, some are literally the disjunctions of other propositions, some are literally the negations of other propositions, and so on; second, propositions cannot stand in relations of logical consequence. Then these proponents of the Russellian orthodoxy are committed to nonstandard conclusions about logic.

For example, they are committed to the conclusion that a disjunction can fail to be a logical consequence of each of its disjuncts (in particular, when disjuncts and disjunction are propositions). And they are committed to the conclusion that a double negation of a claim can fail to be a logical consequence of that claim. And they are committed to the conclusion that two claims can fail to logically imply their conjunction. And so on. I disagree with their conclusions. I think that a disjunction cannot fail to be a logical consequence of each of its disjuncts, and so on. All of this shows that disagreement over the Conditional leads directly to substantive disagreements about logic. And this shows that disagreement over the Conditional is itself substantive, and so not "merely verbal." This is my first reply to Speaks.

My second reply is an argument for the truth of the Conditional. This argument turns on two assumptions, both of which Speaks seems to accept. The first is that there 
are cases of logical consequence involving sentences. The second is that if propositions have logical form, then propositions and sentences share the same logical forms; that is, if propositions have logical form, then sentences and propositions alike can be conjunctions, can be disjunctions, can be negations, etc.; that is, if propositions have logical form, then it is false that, for example, only propositions (but not sentences) can be conjunctions while only sentences (but not propositions) can be disjunctions, etc..

Suppose - from the first assumption - that some sentence $S$ is a logical consequence of some sentence $\mathrm{T}$. Then $\mathrm{S}$ follows from $\mathrm{T}$ solely in virtue of the logical form of $\mathrm{S}$ and the logical form of $\mathrm{T}$. This is because logical consequence just is truthpreservation in virtue of form (34-5). Assume, for conditional proof of the Conditional, that propositions have logical form. Add-from the second assumption - that proposition $p$ has the same logical form as does $\mathrm{T}$ and that proposition $q$ has the same logical form as does S. Then $q$ must be a logical consequence of $p$. This is because, again, logical consequence just is truth-preservation in virtue of form. So the Conditional is true.

\section{V}

Some of what I said about the following claim was sloppy: if structured propositions exist, then there is a full explanation of why they have the representational properties that they have. For example, I said that defenders of structured propositions "believe that there is a full explanation of how each proposition manages to represent things as being a certain way.” Then, as Speaks notes, I attach a footnote describing a particular philosopher as a defender of structured propositions who denies that there is a 
full explanation of how each proposition manages to represent things as being a certain way (154). ${ }^{14}$

The sloppiness in my discussion of the aforementioned claim rendered some of my objections to structured propositions unclear. In this section, I will clarify those objections. More precisely, I will clarify why my conclusion that structured propositions cannot deliver the relevant "full explanation" should be seen, by almost all defenders of structured propositions, as a serious objection to structured propositions.

Consider the proposition that $O$ is $F$. That proposition represents $\mathrm{O}$ as being $\mathrm{F}$. Defenders of structured propositions might say that that proposition's constituents are O and F. But they would not say that its constituents are 7 and being orange. The point generalizes. If there are structured propositions, then (at least some of) the constituents of a structured proposition are intuitively correlated with how that proposition represents things as being.

With this in mind, suppose, for reductio, that a structured proposition's constituents play no role in explaining how that proposition manages to represent things as being a certain way. Then the intuitive correlation between a proposition's constituents and how it represents things as being is a mere coincidence, a coincidence repeatedwithout fail-in each and every structured proposition. But this is not believable. So I conclude that it is false that a structured proposition's constituents play no role in explaining how that proposition manages to represent things as being a certain way. (For the full argument for this conclusion, see 199-205.)

\footnotetext{
${ }^{14}$ Mark Johnston is the philosopher. I said that Johnston "seems to endorse" an account of structured propositions according to which Zipping (he calls it 'predication') has unexplained powers relevant to representation. That was inaccurate. Rather, Johnston presents and motivates such an account, but then explicitly adds that he takes "no fixed view" $(2006,685)$ on whether it is the right account.
} 
If there are structured propositions, each proposition's constituents must play a role in the explanation of how that proposition manages to represent things as being a certain way. So if there are structured propositions, there must be some kind of explanation of how each proposition manages to represent things as being a certain way. That explanation is "full" just in case it does not attribute unexplained powers relevant to representation to a proposition's constituents or to its structure (or to the proposition itself).

The easiest way to see what I mean by "unexplained powers relevant to representation" is by way of example. So recall Zipping, which was discussed in my exchange with Wang; Zipping has unexplained powers relevant to representation. Here is another example, also mentioned by Wang: the proposition that A loves $B$ is the ordered set $<$ A, loving, B, Zip >; that set essentially represents A as loving B; that set does this because of how Zip works; and, given how Zip works, the ordered set $<\mathrm{B}$, loving, A, Zip> essentially represents B as loving A; there is no explanation of Zip's working in these ways; Zip has unexplained powers relevant to representation (cf. 141, 144-5).

A structured proposition results from uniting various entities. Those entities must be united not only so that they make up a single object, but also so that, among other things, the object that they make up represents things as being a certain way. An account of the unity of the proposition tells us what unites entities into an object like that, an object that represents things as being a certain way (155-6). I argue that there is no full explanation of how a structured proposition manages to represent things as being a certain way (133-156). This implies that the unity of the proposition cannot be solved 
without invoking Zip or something else that has unexplained powers relevant to representation.

I think that almost all defenders of structured propositions will reject a Zip-based account of the unity of the proposition (at least in part) because it invokes unexplained powers relevant to representation. So I think that almost all defenders of structured propositions will take my argument for the conclusion that the unity of the proposition cannot be solved without Zip (etc.) as an argument for the conclusion that the unity of the proposition cannot be solved. But there are structured propositions only if there is a solution to the unity of the proposition $(127-9 ; 155-6)$.

So almost all defenders of structured propositions will take my argument for the conclusion that the unity of the proposition cannot be solved without Zip (etc.) as an argument for the conclusion that there are no structured propositions. Therefore, almost all defenders of structured propositions will take my argument for the conclusion that there is no full explanation of how a proposition manages to represent things as being a certain way as an argument for the conclusion that there are no structured propositions. Moreover, I think that the main motivation for defending structured propositions in the first place is their promise to deliver a full explanation of how a proposition manages to represent things as being a certain way (133-9; 160-1).

According to my own account of the nature of propositions, there is no explanation at all of how a proposition manages to represent things as being a certain way (194-9). So I embrace unexplained powers relevant to representation. So why do I myself object to accounts of the unity of the proposition that rely on Zipping or Zip? In Section II of my reply to Wang, I give my reasons for rejecting versions of structured 
propositions that rely on Zipping (154). Those reasons are also reasons to reject versions of structured propositions that locate the unexplained powers in places other than Zipping, such as in Zip. And one more such reason will emerge in my reply to Pautz (§I).

\section{Reply to Pautz}

\section{I}

Wang defends a version of structured propositions that makes use of Zipping. Speaks denies that there is a full explanation of why structured propositions have their representational properties. And Pautz offers a new defense of the claim that there is no explanation of how a proposition manages to represent things as being a certain way. Thus all three seem to endorse unexplained powers relevant to representation.

This surprised me. And this makes me wonder whether I overestimated the degree to which philosophers will balk at my claim that there is no explanation of how a proposition represents things as being a certain way (cf. 207-14). But whether I overestimated this or not, I am happy to add, inspired by Pautz, one more defense of that claim.

Consider the following:

(1) For any $x, x$ instantiates the property being white on the condition that $\mathrm{x}$ is white.

(2) The proposition that the ball is white represents the ball as being white.

Here is Pautz's basic idea: (1) needs no explanation; (1) and (2) are similar in crucial ways; and all of this suggests that (2) needs no explanation. Pautz's basic idea-as well 
as his way of developing it - is insightful. But I shall here develop that idea in my own way.

Suppose that water is analyzed as $\mathrm{H}_{2} \mathrm{O}$. That is, suppose that what it is to be water is to be $\mathrm{H}_{2} \mathrm{O}$. Then it is plausible that nothing explains how water manages to be $\mathrm{H}_{2} \mathrm{O}$. After all, asking for an explanation of how water manages to be $\mathrm{H}_{2} \mathrm{O}$ is akin to asking for an explanation of how water manages to be water.

Suppose that what it is to be the unit set of Socrates is to have exactly Socrates as a member. Then it is plausible that nothing explains how the unit set of Socrates manages to have exactly Socrates as a member. After all, asking how the unit set of Socrates manages to have exactly Socrates as a member is akin to asking how that set manages to be that set.

Suppose that what it is to be the property being white is (among other things) to have the instantiation conditions reported by (1) above. ${ }^{15}$ Then it is plausible that nothing explains how being white manages to have those instantiation conditions. After all, asking how that property manages to have those instantiation conditions is akin to asking how that property manages to be that property.

Suppose that what it is to be the proposition that snow is white is (among other things) to represent snow as being white. Then - with the above examples in mind-it is plausible that nothing explains how that snow is white manages to represent snow as being white. After all, asking for an explanation of how that snow is white manages to represent snow as being white is akin to asking for an explanation of how the proposition that snow is white manages to be the proposition that snow is white.

\footnotetext{
${ }^{15}$ Pautz says: "it is just part of the essence of [being white] to be instantiated by things when they are white."
} 
My account of the nature of propositions says that a proposition is a necessary existent that essentially represents things as being a certain way (191-4). So my account implies that what it is to be the proposition that snow is white is to exist necessarily and to essentially represent snow as being white. And this implies that what it is to be the proposition that snow is white is (among other things) to represent snow as being white. So, given my account of the nature of propositions, it is plausible that nothing explains how that snow is white manages to represent snow as being white. The same goes, mutatis mutandis, for other propositions.

I have argued elsewhere that if my account of the nature of propositions is true, then there is no explanation of how a proposition manages to represent things as being a certain way (194-5). ${ }^{16}$ But I have just argued here for a different conclusion, namely, that if my account of the nature of propositions is true, then it is plausible that there is no explanation of how a proposition manages to represent things as being a certain way. When I say that there is no such explanation, I am biting ice cream cake, not a bullet (cf. 196).

Suppose that you reject my account of the nature of propositions. Suppose that you say, for example, that what it is to be the proposition that snow is white is be the set of possible worlds in which snow is white. Then you should find it plausible that there is no explanation of how the proposition that snow is white manages to have as members exactly those possible worlds in which snow is white. But none of this implies - and I deny (see below) - that you should find it plausible that there is no explanation of how

\footnotetext{
${ }^{16}$ I argue for the conclusion that that snow is white essentially represents snow as being white. I deny that anything explains how that proposition manages to essentially represent snow as being white. This seems to be another counterexample to Speaks's apparent assumption that an argument for a thesis is ipso facto an explanation of that thesis (see §I of my reply to Speaks).
} 
that set manages to represent snow as being white. Parallel comments apply to the view that what it is to be the proposition that snow is white is to be a state of affairs whose constituents include being snow and being white, etc.

Here are three related morals of the above discussion. First, one's account of the nature of propositions can determine whether one should find it plausible that there is no explanation of how a proposition manages to represent things as being a certain way. Second, those who state that it is not plausible that there is no explanation of how a proposition manages to represent things as being a certain way should either retract that statement, or instead add that it is not plausible that what it is to be the proposition that snow is white is (perhaps among other things) to represent snow as being white. Third, those who find it plausible that what it is to be the proposition that snow is white is (perhaps among other things) to represent snow as being white should reject structured propositions and propositions-as-sets-of-possible-worlds.

In support of this third moral, consider:

(A) What it is to be the proposition that snow is white is (perhaps among other things) to represent snow as being white.

(B) There is no explanation of how that snow is white manages to represent snow as being white. (From (A))

(C) If there are structured propositions, then there is some explanation of how that snow is white manages to represent snow as being white.

Therefore,

(D) It is false that there are structured propositions. ((B), (C))

I think that some who have no opinion regarding which particular account of the nature of propositions is correct will nevertheless think that (at least part of) what it is to be the proposition that snow is white is to represent snow as being white. (Compare: 
some without an account of the nature of properties will think that (at least part of) what it is to be a property $\mathrm{F}$ is to be instantiated by all and only Fs.) So some who do not yet know what to think about structured propositions will endorse (A) and therefore - via the reasoning above - should endorse (B) as well.

Recall that if a structured proposition's constituents played no role in the explanation of how that proposition manages to represent things as being a certain way, then the intuitive correlation between a structured proposition's constituents and how it represents things as being would be an incredible coincidence (reply to Speaks, §V). So if there are structured propositions, then a structured proposition's constituents play a role in the explanation of how that proposition manages to represent things as being a certain way. (See 199-205 for the full argument.) This implies (C).

The above argument for (D) - that is, for the conclusion that it is false that there are structured propositions - applies to all versions of structured propositions, and so applies to those versions that purport to deliver only a partial explanation of how a proposition manages to represent things as being a certain way. So this argument counts as one more reason to reject versions of structured propositions that invoke Zipping or Zip or primitive powers relevant to representation located elsewhere in a structured proposition's constituents or structure.

There is an intuitive correlation between the constituents of propositions-as-setsof-possible-worlds and how those sets are supposed to represent things as being. For example, the members of the set of possible worlds that is alleged to represent snow as being white are all and only the possible worlds in which snow is white (as opposed to, say, all and only the possible worlds in which New York is larger than London). So, lest 
that intuitive correlation be an incredible coincidence, if propositions are sets of possible worlds, a proposition's members play a role in the explanation of how that proposition manages to represent things as being a certain way (see 199-205). Thus:

$\left(\mathrm{C}^{*}\right)$ If propositions are sets of possible worlds, then there is some explanation of how that snow is white manages to represent snow as being white.

$\left(\mathrm{C}^{*}\right)$ and (B) jointly imply that it is false that propositions are sets of possible worlds.

\section{II}

My claims about the nature of propositions can be stated using Pautz's expression "constitutive essence." The constitutive essence of, for example, that snow is white is existing necessarily and essentially representing snow as being white. I think that an account of the nature of a proposition - or, if you prefer, an account of a proposition's constitutive essence-explains the other features that are distinctive of that proposition (191-4). For example, I think that the constitutive essence of that snow is white explains why, necessarily, that proposition is true if and only if snow is white.

Pautz asks whether there is an analysis of a proposition's constitutive essence. I never considered this question in Propositions. But I do think that the constitutive essences of some propositions have analyses. For suppose not only that the constitutive essence of that snow is white is existing necessarily and representing snow as being white, but also that snow is analyzed as $\mathrm{H}_{2} \mathrm{O}$ that is in state $\mathrm{S}$. Then the constitutive 
essence of that snow is white can be analyzed as existing necessarily and representing $\mathrm{H}_{2} \mathrm{O}$ that is in state $\mathrm{S}$ as being white. ${ }^{17}$

This analysis of the constitutive essence of that snow is white is predicated on analyzing representing snow as being white as representing $\mathrm{H}_{2} \mathrm{O}$ that is in state $\mathrm{S}$ as being white. Pautz would endorse an additional analysis of representing snow as being white, an analysis that turns on analyzing representation itself, and doing so in terms of, among other things, a proposition's being true in virtue of things being a certain way.

Pautz says that his analysis of representation implies that propositions and properties have parallel constitutive essences. He sees this as a virtue of his analysis. But I do not see this as a virtue (or as a vice). This is in part because I deny that propositions are 0 -place properties (86). This denial undermines what I take to be the most compelling reason to expect propositions and properties to have parallel constitutive essences.

Moreover - as Pautz himself notes - I have my own reason to reject his analysis. I take a proposition's being true to be analyzed as that proposition's representing things as being a certain way and, moreover, things being that way (20, esp. 20n10). So I cannot turn around and then analyze a proposition's representing things as being a certain way in terms of, among other things, that proposition's being true in virtue of things being that way.

\section{III}

\footnotetext{
17 As Pautz says, giving an analysis of having a representational property does not, all by itself, explain why something has that property. For consider those who-like Soames and King - demand an explanation of how that snow is white manages to represent snow as being white. Their demand is not met by the reply that that proposition represents $\mathrm{H}_{2} \mathrm{O}$ that is in state $\mathrm{S}$ as being white.
} 
Pautz says:

...consider the total non-doxastic facts about me while viewing the tomato. They include the first-person fact that the tomato looks clearly round to me, the fact that the sentence "Hm, that tomato sure is round" runs through my inner voice, the fact that all my behavioral dispositions are appropriate to the presence of a round thing, and much else. Is there a "possible world" where all these phenomenalfunctional facts are the same, and yet I "really" bear the believing relation to the proposition that the tomato is triangular, rather than the proposition that the tomato is round? This would have to be a super secret belief: not only would it not show up in my overt behavioral dispositions, it wouldn't even show up in my inner experiential life (e. g. my "inner speech", imagery, etc.)! This seems impossible.

Pautz's reasoning is persuasive. So let us agree that an agent's non-doxastic states necessitate that agent's doxastic states.

Pautz then says: "Indeed, a full description of the non-doxastic phenomenalfunctional facts about me ground the fact that I believe that the tomato is round." But I deny this. That is, I deny that an agent's standing in the believing relation to a proposition is grounded by that agent's non-doxastic states alone. I claim, instead, that an agent's standing in the believing relation to a proposition is grounded by that agent's (existing and) having certain non-doxastic states along with that proposition's (existing and) representing things as being a certain way. ${ }^{18}$

I make this claim for two reasons. To see the first reason, let $p$ be the proposition that represents a given tomato as being round. And let A be an agent who has the nondoxastic (phenomenal-functional) states described by Pautz in the above passage. Agent A stands in the believing relation to $p$. But if - per impossibile $-p$ had represented that

\footnotetext{
${ }^{18}$ For what it is worth, I deny that there is a single grounding relation such that both doxastic facts stand in that relation to non-doxastic facts and sets stand in that relation to their members, and so on, for each alleged instance of grounding (unless that relation is disjunctively analyzed as the way in which the doxastic depends on the non-doxastic or the way in which sets depend on their members, etc.) (cf. Merricks, 2008, 336).
} 
tomato as being triangular, then $\mathrm{A}$ would not have stood in the believing relation to $p$, despite having the aforementioned non-doxastic states. This suggests that A does not stand in the believing relation to $p$ solely in virtue of having those non-doxastic states. It suggests, instead, that what grounds A's standing in the believing relation to $p$ includes not only A's having those non-doxastic states, but also $p$ 's representing the tomato as being round.

My second reason turns on an analysis of an agent's having the belief that a given tomato is round. I say that this is analyzed as that agent's standing in the believing relation to (perhaps among other things) a proposition that represents that tomato as being round (26). In light of this analysis, I conclude that whatever grounds an agent's having a belief must involve not only that agent and her or his non-doxastic states, but also the relevant proposition and how it represents things as being.

Again, I deny that an agent's standing in the believing relation to a proposition is grounded in that agent's non-doxastic states alone. So I reject Pautz's Simple Grounding View. Pautz says that the Simple Grounding View has three drawbacks. Since I reject that view, I am not troubled by its having drawbacks. But it is worth considering whether there are analogues of those drawbacks with regard to what I do accept, namely, that an agent's non-doxastic states necessitate (but do not ground) that agent's standing in the believing relation to a proposition. ${ }^{19}$

The first drawback of the Primitive Grounding View is that it seems to imply "a swarm of brute 'grounding laws"' such as:

\footnotetext{
${ }^{19}$ Each proposition exists necessarily and essentially represents things as being a certain way. This is why my doxastic states can necessitate my standing in the believing relation to a proposition without, on their own, grounding my standing in that relation to that proposition.
} 
$\left(\mathrm{G}^{*}\right)$ Necessarily, if the non-doxastic facts about a subject are so-and-so, then those facts ground the fact that the subject bears the primitive belief relation to proposition $p .^{20}$

Here is the necessitation-not-grounding analogue of $\left(\mathrm{G}^{*}\right)$ :

(G1) Necessarily, if the non-doxastic facts about a subject are so-and-so, then the subject bears the primitive belief relation to proposition $p$.

One might object that I am committed to "a swarm of brute necessities" along the lines of (G1).

But consider:

(G2) Necessarily, if the non-doxastic facts about a subject are so-and-so, then the subject is in a certain doxastic state.

Everyone should accept (G2). (For a defense of (G2), see the passage from Pautz quoted above.)

Suppose that the necessitation described in (G2) is brute. Then everyone is committed to a "swarm of brute necessities." So this problem - if it is a problem - has nothing to do with (G1) in particular. Suppose, on the other hand, that the necessitation described in (G2) is not brute. Then the necessitation described in the analysis of $(\mathrm{G} 2)$ is not brute. Then the necessitation described in $(\mathrm{G} 1)$ is not brute, since-so I say- $(\mathrm{G} 1)$ is the analysis of $(\mathrm{G} 2)$.

Pautz says: "In general, grounding obeys a congruence constraint: if a fact involves a certain real item, then the facts which ground that fact also involve that item." His second drawback for the Primitive Grounding View is that it violates this congruence constraint for grounding. But there is no analogous congruence constraint for

\footnotetext{
${ }^{20}$ Pautz uses 'primitive', when applied to believing, to mean not "definable in belief-independent (e.g., experiential-functional-causal) terms." Let us stipulate, for the sake of argument, that believing is thus primitive.
} 
necessitation. For example, Pautz's being a philosopher necessitates all dogs being dogs; Pautz's being a philosopher does not "involve" all dogs being dogs; none of this is a problem.

Here is the necessitation-not-grounding analogue of Pautz's final drawback for the Simple Grounding View:

Consider this [necessary] connection: certain non-doxastic facts about me (including facts about my dispositions to use arithmetical vocabulary) [necessitate] the fact that I bear the believing relation to the proposition that two plus two is four, rather than the proposition that two quus two is four. Absent some explanation, this [necessary] connection looks arbitrary. But it's hard to see how Merricks might explain it.

This analogue assumes that we really do believe that two plus two is four, rather than that two quus two is four. Grant that assumption for the sake of argument. Recallas Pautz argues - that everyone should accept that an agent's doxastic states are necessitated by that agent's non-doxastic states. Then conclude that everyone has the sort of problem just described.

That is, certain non-doxastic facts about an agent (including facts about the agent's dispositions to use arithmetical vocabulary) necessitate the fact that that agent has the belief that two plus two is four, rather than the belief that two quus two is four. Absent some explanation, this instance of necessitation looks arbitrary. But it is hard to see how anyone might explain it, whether or not they believe in propositions. ${ }^{21}$

\section{References}

Bergmann, Michael (1996) "A New Argument from Actualism to Serious Actualism," Noûs 30: 356-359.

\footnotetext{
${ }^{21}$ Thanks to Elizabeth Barnes and Ross Cameron for helpful comments on an earlier draft.
} 
Hanks, Peter (2015) Propositional Content (Oxford: Oxford University Press).

Johnston, Mark (2006) “Hylomorphism,” Journal of Philosophy 103: 652-698.

King, Jeffrey C. (2007) The Nature and Structure of Content (Oxford: Oxford University Press).

Lewis, David (1992) "Critical Notice of D. M. Armstrong's A Combinatorial Theory of Possibility," Australasian Journal of Philosophy 70: 211-24.

Merricks, Trenton (2008) "Replies to Cameron, Schaffer, and Soames," Philosophical Books 49: 328-343.

Soames, Scott (2015) Rethinking Language, Mind, and Meaning (Princeton: Princeton University Press).

Thomson, Judith Jarvis (1998) “The Statue and the Clay,” Noûs 32: 149-73. 